\title{
Error Correction Mechanisms for Transactional Script Smart Contracts
}

\author{
By Catherine Martin Christopher
}

\section{INTRODUCTION}

The Australian wheat industry is notoriously inefficient. ${ }^{1}$ A sale of wheat between farmer and wholesaler can involve up to 27 parties, ${ }^{2}$ and it is quite common for a farmer to wait sixty days - sixty days! - between delivering the wheat and receiving payment. ${ }^{3}$ In December 2016, though, one farmer in New South Wales sold 24 tonnes of wheat to a wholesaler and was paid in minutes, rather than days or months. ${ }^{4}$ This streamlined sale was made possible because a technology coordinator called AgriDigital automated many of the transaction steps. ${ }^{5}$ The coordinator electronically linked many steps that are traditionally performed by individual actors: The wheat was weighed electronically at delivery, with the weight then automatically input to calculate payment according to a pre-agreed-upon price, which in turn automatically

\footnotetext{
* Professor of Law, Associate Dean for Bar Success, Texas Tech University School of Law. J.D., University of Pittsburgh. The author wishes to thank Shaanan Cohney, Farshad Ghodoosi, Heather Hughes, and Carla Reyes for their helpful comments on earlier drafts; the Women Faculty Writing Program of Texas Tech University for creating space and time to write; Patricia Cabrera-Sopo for research assistance; my students and colleagues at Texas Tech who asked excellent clarifying questions; and the Texas Tech University School of Law for its support.

1. You knew that, right? See Michael Bacina, When Two Worlds Collide: Smart Contracts and the Australian Legal System, 21 NO. 8 J. INTERNET L. 1, 19 (2018).

2. Id.

3. Katherine Davison, Blockchain Technology: Leading the Way to Shorter Payment Terms in Agriculture, AGRIDigiTAL (May 24, 2019, 4:40 PM), https://blog.agridigital.io/blog/blockchaintechnology-eading-the-way-to-shorter-payment-terms-in-agriculture [https://perma.cc/E2BJ-UHQJ].

4. James Eyers, Wheat Farmers Trial Blockchain to Sell Grain and Find It is Fast and Reliable, FIN. REV. (Dec. 21, 2016, 11:00 PM), https://www.afr.com/technology/wheat-farmers-trialblockchain-to-sell-grain-and-find-it-is-fast-and-reliable-20161206-gt57lx [https://perma.cc/6J8GNZVQ]; Gregor Heard, Blockchains a Glimpse of Future Payment System, QuEENSLAND COUNTRY LIFE (Dec. 14, 2016, 2:00 PM), https://www.queenslandcountrylife.com.au /story/4355255/blockchains-a-glimpse-of-future-payment-system/?cs=4733 [https://perma.cc/3FWREVP5].

5. See Solving for Supply Chain Inefficiencies and Risks with Blockchain in Agriculture, CBH GRP. \& AGRIDIGITAL 2-3 (Nov. 2017), https://assets.website-files.com/ 5acb6c048451816da066ad80/5af2a0068f5865bb84d047ff_AgriDigital\%20CBH\%20Blockchain\%20 White\%20Paper\%20Final.pdf [https://perma.cc/6ANW-FDFH].
} 
triggered the release of funds from buyer to seller. ${ }^{6}$ In fact, as the payment was transferred to the farmer, title of the grain was digitally transferred to the buyer simultaneously. ${ }^{7}$ This streamlined transaction utilized distributed ledger technology, which allowed the execution of the sale and payment to take place with the involvement of only 9 parties, instead of $27 .{ }^{8}$

In this instance, the parties had agreed ahead of time to all the terms of the contract, and that agreement was then coded into computer-readable language. ${ }^{9}$ Once the performance of the contract (the delivery of the wheat) was electronically verified, the computer-coded contract then automatically triggered payment from the buyer to the seller, reducing the number of players and thus the opportunities for delay and error. ${ }^{10}$ The distributed ledger technology upgraded an old-fashioned transaction with modern technology, making the transaction significantly more efficient and secure.

This transaction, automated by computer coding, is an example of a smart contract. Although there is no one agreed-upon definition, all descriptions of smart contracts seem to agree that a smart contract is an agreement incorporating automated performance. ${ }^{11}$ A vending machine is a classic example of a smart contract: ${ }^{12}$ it's standing there, offering a soda or a candy

\footnotetext{
6. Id. at 3 .

7. Id.

8. Bacina, supra note 1 , at 19.

9. See Solving for Supply Chain Inefficiencies and Risks with Blockchain in Agriculture, supra note 5 , at 3 .

10. Id. at 4. According to the CEO of the technology coordination firm, AgriDigital, its platform has accommodated over \$2 billion in transactions between the firm's founding in 2016 and the end of 2019. Emma Weston (@emmamweston), TwITTER (Dec. 26, 2019, 5:34 PM), https://twitter.com/emmamweston/status/1210343160351641600 [https://perma.cc/Q98U-GPBF]. AgriDigital expanded to the United States in August, 2019. Katherine Davison, AgriDigital Launches in United States as the North American Grain Harvest Gets Underway, AGRIDigITAL (Aug. 30, 2019, 4:50 PM), https://blog.agridigital.io/blog/agridigital-launches-in-united-states-as-the-north-americangrain-harvest-gets-underway [https://perma.cc/6K9E-KR7K].

11. See, e.g., J.G. Allen, Wrapped and Stacked: "Smart Contracts" and the Interaction of Natural and Formal Language, 14 EUR. REV. CONT. L. 307 (manuscript at 3), https://papers.ssrn.com/sol3/papers.cfm?abstract_id=3297425 ("a single instrument, written in formal language, embodying both the contract as such and its automated mechanism of performance"); Helen Eenmaa-Dimitrieva \& Maria José Schmidt-Kessen, Smart Contracts: Reducing Risks in Economic Exchange with No-Party Trust?, 10 EUR. J. RISK REG. 245, 245 ("self-executing agreements based on blockchain technology"); Max Raskin, The Law and Legality of Smart Contracts, 1 GEO. L. TECH. REV. 305, 309 (2017) (“A smart contract is an agreement whose execution is automated.").

12. Many sources use this example. E.g., NicK SZABo, THE IDEA OF SMART Contracts (1997), https://www.fon.hum.uva.nl/rob/Courses/InformationInSpeech/CDROM/Literature/LOT winterschool2006/szabo.best.vwh.net/idea.html [https://perma.cc/C2G8-Y99H]; Raskin, supra note 11, at 314-16 (including delightful historical examples of vending machines, including a holy water dispenser developed in 215 B.C. and a "book-dispensing machine" invented in the 17th century to evade laws prohibiting people from selling offensive material); Kevin Werbach \& Nicolas Cornell,
} 
bar for a specific price, and when someone accepts the offer by putting in the money, the machine automatically delivers the treat without needing any additional input or verification.

A vending machine is a mechanical example of a smart contract, but smart contracts are becoming increasingly digitized. For example, starter interrupters in leased cars have been around for over a decade: If a lessee fails to make a payment on a leased vehicle that is equipped with an internetenabled starter interrupter, the lessor can electronically (and remotely) instruct the starter interrupter to prohibit the vehicle from starting. ${ }^{13}$

Increasingly, smart contract innovation is focused on the intersection with another technological breakthrough, distributed ledger technology. A distributed ledger is an electronic form of recordkeeping that's being maintained not by a single computer (or server or company or government), but instead is being maintained on a number of computers all networked together. ${ }^{14}$ When a new entry to the ledger is proposed, the computers in the network all work independently to verify the transaction. Once a majority of the network verifies the transaction, the requisite consensus is reached and the ledger entry is added. ${ }^{15}$ Distributed ledger technology only works forward, though: New transactions are added to the ledger, but previous entries are not

Contracts Ex Machina, 67 DuKE L.J. 313, 323-24 (2017); Jonathan G. Rohr, Smart Contracts and Traditional Contract Law, Or: The Law of the Vending Machine, 67 CLEV. ST. L. ReV. 71, 77-78 (2019); Tatiana Cutts, Smart Contracts and Consumers, 122 W. VA. L. REV. 389, 396-97 (2019); Sai Agnikhotram \& Antonios Kouroutakis, Doctrinal Challenges for the Legality of Smart Contracts: Lex Cryptographia or a New, 'Smart' Way to Contract?, 19 J. HigH TECH. L. 300, 312 (2019); Mark Verstraete, The Stakes of Smart Contracts, 50 LOY. U. CHI. L.J. 743, 756-57 (2019).

13. Christina M. Mulligan, Personal Property Servitudes on the Internet of Things, 50 GA. L. REV. 1121, 1160 (2016). This application was perhaps first theorized by Nick Szabo in 1997. See Szabo, supra note 12. As Szabo realized, and as experience has borne out, starter interrupters can inhibit use of a vehicle at crucial moments. See How Auto Dealers Can Use GPS and "Starter Interrupter" Tech to Disable Your Car, CBS NEwS (Mar. 21, 2017, 6:56 AM), https://www.cbsnews.com/news/car-repossession-device-starter-interrupter-auto-dealer-car-creditcity/ [https://perma.cc/Z5HH-UQEN].

14. Jesse Marks, Distributed Ledger Technologies and Corruption the Killer App?, 20 CoLuM. SCI. \& TECH. L. REV. 42, 47 (2018). The first functional distributed ledger technology was the blockchain, upon which the Bitcoin system operates. See Satoshi Nakamoto, Bitcoin: A Peer-toPeer Electronic Cash System (2008), https://bitcoin.org/bitcoin.pdf [https://perma.cc/VZ23-RHTP]. We thought Bitcoin was cool, but the blockchain technology underpinning it will likely eclipse Bitcoin itself in scope of innovation and utility. See Jay Cassano, What Are Smart Contracts? Cryptocurrency's Killer App, FAST Co. (Sept. 17, 2014), https://www.fastcompany.com/ 3035723/smart-contracts-could-be-cryptocurrencys-killer-app\#: :text=Smart\%20contracts\%20are\% 20computer\%20programs, beyond $\% 20$ simple $\% 20$ transfers $\% 20$ of $\% 20$ funds [https://perma.cc/HCJ2HPZ5]. Another popular distributed ledger technology - capable of hosting transactional scripts - is Ethereum. See What is Ethereum?, ETHEREUM, ethereum.org/en/what-is-ethereum [https://perma.cc/S36D-NUF4] (last visited Jan. 24, 2020).

15. See Marks, supra note 14, at 47. 
changed. ${ }^{16}$ A transfer of funds from a wheat buyer to a wheat farmer cannot be reversed - the farmer would have to initiate a new transaction to send the funds back to the buyer. ${ }^{17}$

Ledgers are not limited to tracking monetary transactions, though. Ledgers can track obligations and rights as well. Accounting ledgers regularly track obligations like loan balances and accounts receivable, and a county's deed records are a form of ledger tracking property rights and transfers. Distributed ledger technology innovators are currently pursuing a variety of applications, including location and ownership of commodities, ${ }^{18}$ real estate, ${ }^{19}$ and health care. ${ }^{20}$

A smart contract that utilizes distributed ledger technology as its operational platform should be referred to as a transactional script. ${ }^{21}$ Many writers tend to use the more general (and admittedly catchier) phrase "smart contract" when referring to transactional scripts, ${ }^{22}$ but it is time for this to

16. Id.

17. There have been exceptions to this truism that distributed ledgers only work forwards. Technology developers working on both Bitcoin and Ethereum have engineered "hard forks" that have the effect of reverting the distributed ledgers to earlier versions. See Paul Vigna, Fund Based on Digital Currency Ethereum to Wind Down After Alleged Hack, Wall ST. J. (June 17, 2016, 7:27 PM), https://www.wsj.com/articles/investment-fund-based-on-digital-currency-to-wind-downafter-alleged-hack-1466175033 [https://perma.cc/NQ67-4SGF]; Paul Vigna, Bitcoin Rival Ethereum Gains Traction, WALL ST. J. (June 20, 2016, 11:28 PM), https://www.wsj.com/articles/bitcoin-rivalether-gains-traction-1466461279 [https://perma.cc/YA67-B9G5]. Doing so is extremely controversial for users, however, since one of the hallmarks of distributed ledger technology is that prior entries are immutable. Thibault Schrepel, Is Blockchain the Death of Antitrust Law? The Blockchain Antitrust Paradox, 3 GeO. L. TeCH. REV. 281, 330-31 (2019). Protocols can also be designed to allow for reversals.

18. E.g., Katherine Davison, Why Is Proof of Location Important for Digital Assets?, AgriDigital (Jan. 8, 2019, 3:27 PM), https://blog.agridigital.io/blog/why-is-proof-of-locationimportant-for-digital-assets [https://perma.cc/4KWK-FYYG] [hereinafter Davison, Why Is Proof of Location Important for Digital Assets?] (discussing expansion of the wheat contracting transactional script to "the oil and gas industry, [to] the metals industry, but also [to] very niche industries like the Pearl Industry, the Tapioca Industry of Thailand.").

19. E.g., Blockchain in Commercial Real Estate, DeloitTe 10 (2017), https:// www2.deloitte.com/content/dam/Deloitte/us/Documents/financial-services/us-dcfs-blockchain-increthe-future-is-here.pdf [https://perma.cc/Q33U-HZ32].

20. Blockchain: Opportunities for Healthcare, DELOITTE (2016), https:// www2.deloitte.com/us/en/pages/public-sector/articles/blockchain-opportunities-for-health-care.html [https://perma.cc/79NU-EQLL].

21. See Shaanan Cohney \& David A. Hoffman, Transactional Scripts in Contract Stacks, 105 MinN. L. REV. 319, 323 (2020) (“A transactional script is a persistent piece of software residing on a public blockchain. When executed as a part of an exchange, the code effectuates a consensus change to the state of a ledger.")

22. E.g., @iang_fc, TwITTER (Jan. 29, 2020, 3:24 AM), https://twitter.com/iang_fc/status/1222450430413807616 [https://perma.cc/DD7C-DYCR] ("Nobody's been happy with the term 'smart contracts.' B[e]c[ause] of the strong influence of Nick 
change. ${ }^{23}$

Back to our primary example: The Australian wheat transactional script example discussed here was a carefully controlled pilot transaction. ${ }^{24}$ The seller and buyer knew each other, and a local technology coordination firm worked closely with the parties to design and oversee the transaction. ${ }^{25}$ The parties agreed to the terms of the transaction in advance, the coordination firm coded the agreement onto a private distributed ledger managed and monitored by firm employees. Had anything gone wrong with the transaction - had the scale malfunctioned and not correctly weighed the delivery or had a bug in the coding prevented payment - the parties no doubt would have worked together offline to rectify any errors in execution. The transactional script did not change anything about the fundamental nature of the transaction between buyer and seller; it merely provided a technological upgrade that streamlined the execution of the agreement by automating steps that would otherwise have been performed manually.

The wheat transaction is a current example of a transactional script smart contract, but this Article addresses the next generation, those in which a few contractual knowns become unknowns. For example, whereas in the Australian wheat example, the parties knew each other IRL ${ }^{26}$, it is not difficult to imagine that a next-generation transactional script may be between two parties who have not verified one another's identities. Or, whereas the arrival of the wheat and its weight were verifiable, quantifiable events, parties may in the future wish to apply transactional script technology to more qualitative agreements. It is also entirely possible - perhaps even inevitable ${ }^{27}$ - that transactional script code will contain a bug or a typo-resulting in, for example, payment directed to a stranger to the contract, leaving a seller without compensation and a buyer without incentive to pay again.

In other words, this Article explores the implications of transactional scripts used in situations where there is less than total trust between the parties.

[Szabo]'s writings, and the closeness of the idea in Bitcoin script, the term stuck. It's also good copy material, makes readers feel smart.”).

23. See infra Part II.A.

24. Solving for Supply Chain Inefficiencies and Risks with Blockchain in Agriculture, supra note 5 , at $2-3$.

25. See id. The technology coordination firm, AgriDigital, specializes in agricultural transactions. See AgRiDigitAL, www.agridigital.io [https://perma.cc/Z3H5-H9BZ] (last visited Jan. 24, 2021).

26. "In real life," for the uninitiated.

27. See Cohney \& Hoffman, supra note 21, at 320-21 ("Even carefully audited, well tested software will (almost always) contain bugs. Therefore, and despite our best efforts ... [s]mart contracts will (almost always) contain bugs!") 
In particular, this Article asks the question of how parties to these nextgeneration transactional scripts can seek redress and remedies in the event that the transactional script does not perform according to the parties' intent. ${ }^{28}$ Until parties feel safe that any errors can be corrected, large-scale implementation of transactional scripts will be hobbled. ${ }^{29}$

Part II of this Article articulates why the term "transactional scripts" is preferable to "smart contracts" and describes the utility and potential of transactional scripts. Part III identifies several factors that hinder greater expansion of the use of transactional scripts. It goes on to identify uncertainty of enforcement ${ }^{30}$ as the most important barrier to transactional script innovation, finding that parties will be reluctant to entrust bigger and more complex transactions to transactional scripts until the parties are comfortable that an external mechanism is capable of correcting errors in the execution of the transaction. This lack of reliable enforcement mechanisms is a problem exacerbated by the characteristic of distributed ledger technology, which is to move only forward, preventing revisions or reversals of preexisting entries. ${ }^{31}$ Part IV explores and critiques possible mechanisms that may be able to provide error correction, including statutory law, private law, online dispute resolution, public/private regulatory partnership, and common law. Part V concludes the Article, noting that the expansion of transactional scripts' utility will be tethered to the security provided by available error-correction mechanisms. Only as contracting parties become assured that the integrity of their transactional intent will be effectuated will transactional scripts be adopted for use.

28. This Article aims to address situations in which both or all parties' intent is not met (both parties are unhappy with the transactional script's execution), as well as situations in which one or less than all parties' intent is not met (at least one party is satisfied but the other(s) is/are not).

29. See Catherine Martin Christopher, The Bridging Model: Exploring the Roles of Trust and Enforcement in Banking, Bitcoin, and the Blockchain, 17 NEV. L.J. 139, 157-58 (2016) (noting that contracts are only entered into if the parties have a combination of trust in one another's performance and reliable external enforcement mechanisms from which to seek redress in the event of breach).

30. Some sources refer to smart contracts as being "self-enforcing," meaning that once programmed, the smart contract will execute without further human involvement. E.g., Kyung Taeck Minn, Towards Enhanced Oversight of "Self-Governing" Decentralized Autonomous Organizations: Case Study of the DAO and Its Shortcomings, 9 N.Y.U J. INTELL. PROP. \& ENT. L. 139, 146 (2019) ("The smart contract, in addition to its self-executing and irreversible properties, is also self-enforcing because withholding payment when the relevant condition is satisfied is not possible if the smart contract code does not allow for it."). That is not the meaning intended here. Rather, "enforcement" as used in this Article refers to the ability of the parties to seek correction of erroneous performance, so that the parties' intent for the contract will be enforced.

31. KeVIn Werbach, The BlockChain AND the NeW ArchiteCture OF Trust 101 (2018). 


\section{TRANSACTIONAL SCRIPTS: A NEW WAY FORWARD}

This Part articulates why the term "transactional scripts" is a better descriptor than "smart contracts," and goes on to explore current and potential applications for transactional scripts.

\section{A. Terminology}

A "smart contract" is any agreement that incorporates automated performance. ${ }^{32}$ Those that do so via distributed ledger technology deserve their own specific term, because the term "smart contract" implies that the agreement can do more than it actually can. ${ }^{33}$ In one sense a contract is a set of if-thens - if dollar, then soda - and the fact that a contract is recorded via computer code does not revolutionize the underlying agreement. The adjective "smart," on the other hand, implies a technology that does more than its human operators recognize: a "smart" watch with features the user can discover and upgrade over time; a "smart" television that can algorithmically recognize a viewer's entertainment preferences and recommend new shows to watch. A "smart" contract doesn't do any of this. "Smart" contracts are merely pre-arranged agreements that respond to certain stimuli in predetermined ways, changing the state of some electronic asset upon receipt of a pre-determined input. ${ }^{34}$ They do not innovate, or adapt, or problem-solve; they merely wait for inputs and respond upon receipt. ${ }^{35}$

"Transactional script" is a better descriptor for these specific smart contracts. ${ }^{36}$ It's a better descriptor, first and foremost, because it's a boring phrase and will discourage flights of fancy about sentient computers and contracts. ${ }^{37}$ Instead, "transactional" refers to the transactive nature of the agreement - if delivery, then payment-and which captures the sense of movement (of money, or goods, or ownership) only upon the input of a catalytic event. "Scripts" here refers merely to the computer code by which the pre-arranged contract is reduced to a form of writing. As a whole, the term

32. SZABO, supra note 12 .

33. E.g., @iang_fc, supra note 22.

34. See Cohney \& Hoffman, supra note 21, at 322-23.

35. See, e.g., Vitalik Buterin, A Next-Generation Smart Contract and Decentralized Application Platform, ETHEREUM (2013), https://ethereum.org/en/whitepaper/ [https://perma.cc/7LGD-4SJN].

36. See Cohney \& Hoffman, supra note 21, at 323.

37. Vitalik Buterin, founder and chief developer of the Ethereum blockchain, tweeted in 2018, "To be clear, at this point I quite regret adopting the term 'smart contracts.' I should have called them something more boring and technical, perhaps something like 'persistent scripts."' @ VitalikButerin, TWITTER (Oct. 13, 2018, 12:21 PM), https://twitter.com/VitalikButerin/status/1051160932699770882 [https://perma.cc/AJJ3-MB6Q]. 
"transactional scripts" conveys the sense that the computer code waits passively for input, upon receipt of which it will automatically change some state to which it has access.

The Australian wheat transaction described above, therefore, is best described as a transactional script rather than a "smart contract," because its terms were encoded on, and its automated performance facilitated by, a distributed ledger technology. ${ }^{38}$ This Article will use the more specific term "transactional script" instead of the more general "smart contract," even as many of the quotations and sources cited herein use the term "smart contract." 39 (This Article will also generally use the term "distributed ledger technology" rather than "blockchain," as a blockchain is a kind of distributed ledger technology. ${ }^{40}$ )

\section{B. Utility}

Many people find transactional scripts appealing for philosophical reasons, that the distributed technology heralds a libertarian utopia where autonomous individuals can transact between each other without state oversight or authorization. ${ }^{41}$ Others are concerned that transactional scripts may enable (purposefully or by accident) transactions that would be unenforceable or illegal if they were attempted via lower-tech methods. ${ }^{42}$ Because distributed ledger technology is pseudonymous, there may be no way to ensure the contracting parties' capacity or intent to enter into the agreement, such as contracts entered into by minors. Because transactional scripts automatically execute after the code is made live, and because the results of

38. The transaction was recorded on and effectuated by a private blockchain, in turn facilitated by the Ethereum platform. Heard, supra note 4.

39. E.g., Raskin, supra note 11, at 306.

40. Several identifiable features are among the hallmarks of blockchain and distributed ledger technology: the distributed structure, the consensus mechanism, and the immutability of recordkeeping. Schrepel, supra note 17, at 330-31. Other hallmark features are that transactions are conducted peer-to-peer (because the network records the transactions but does not act as a central processor), and that users on the network are pseudonymous (meaning each user is identified by a specific but anonymized key, akin to an account number). Id.

41. See Dmitri Kosten, Bitcoin Mission Statement, or What Does It Mean[,] Sharing Economy and Distributed Trust? (Oct. 31, 2015) (manuscript at 5, 13), https://papers.ssrn.com/ sol3/papers.cfm?abstract_id=2684256 [https://perma.cc/MC8D-LFPE] (crediting technological advancements in the means of production with the transformation from feudalism to capitalism, and suggesting that distributed ledger technology and smart contracts are similarly "poised to disrupt the existing system [of financial control].").

42. Kolber refers to the technology's ability to act as "artificial responsibility," and warns in a subheading that "Artificial Responsibility Can Be Dangerous (Don't Be Lulled by the Absence of Scary Robots)." Adam J. Kolber, Not-So-Smart Blockchain Contracts and Artificial Responsibility, 21 STAN. TECH. L. REV. 198, 231 (2018). 
transactional scripts are tamper-resistant on the distributed ledger, there may be no way to undo the results of an agreement that would otherwise have been illegal or unenforceable. ${ }^{43}$

Still others argue that transactional script technology eliminates valuable features of lower-tech contracting. ${ }^{44}$ The option of efficient breach may be eliminated in a transaction utilizing a transactional script, since a transactional script will automatically execute according to its terms. ${ }^{45}$ Traditional contracting also has in place ready mechanisms for consumer protection; moving contracting to decentralized digital platforms outside the current legal and business framework may well mean a lack of consumer protection for weaker parties. ${ }^{46}$

Why bother developing transactional scripts, then? In short, they are more efficient and secure. Pre-programmed terms and automated execution can streamline routine transactions, speed performance and payment, and confirm origins and locations. ${ }^{47}$ Transactional scripts also allow parties to transact peer-to-peer around the globe, across international borders (which in turn raises potential compliance concerns.)

As of this writing, transactional scripts' utility is promising but largely

43. See Werbach \& Cornell, supra note 12, at 367-74 (identifying potential problems with mutual assent, consideration, capacity and legality); Scott A. McKinney, Rachel Landy \& Rachel Wilka, Smart Contracts, Blockchain, and the Next Frontier of Transactional Law, 13 WASH. J.L. TECH. \& ARTS 313, 326-36 (2018) (identifying potential problems with formation, allocation of risk, indemnification, flexibility, enforcement, state laws, third party intrusion, statute of frauds, regulatory compliance, and the unauthorized practice of law); Bacina, supra note 1, at 20-21 (identifying potential problems with requirements that contracts be in writing, notification of terms, identifying parties, illegality, enforcement, liability of the author); Alexander Savelyev, Contract Law 2.0: "Smart" Contracts as the Beginning of the End of Classic Contract Law 19-20 (Higher Sch. of Econ. Rsch., Working Paper, Paper No. WP BRP 71/LAW/2016, 2016), https://papers.ssrn.com/ sol3/papers.cfm?abstract_id=2885241 [https://perma.cc/8P4M-8TS8] (noting that invalid consent or intent does not impact a smart contract's validity, along with the possibility of smart contracts for illegal purposes); Lauren Henry Scholz, Algorithmic Contracts, 20 STAN. TECH. L. REV. 128, 153-57 (2017) (identifying problems with mutual assent, consideration, and defenses to formation); Contracts on the Blockchain, InST. InT'L Fin., GetTing SMART, 9 (May 2016), https://www.iif.com/portals/0/Files/private/32370132_smartcontracts_report_may_2016_vf.pdf [http s://perma.cc/K5JX-LWBH] (identifying legal issues regarding jurisdiction, demonstrating acceptance of offers, whether coding smart contracts constitutes the unauthorized practice of law, and consumer protection, among other concerns).

44. In addition to the examples noted in this paragraph, see infra Parts III.B. and C.

45. Savelyev, supra note 43 , at 15,18 .

46. Id. at 19-20.

47. See Sarah Jane Hughes, Do Blockchain Technologies Make Us Safer? Do Cryptocurrencies Necessarily Make Us Less Safe?, 55 TEX. INT'L L.J. 373, 388-89 (2020); Youngju Yun, The Influence of Blockchain Technology on Fraud and Fake Protection, OLD DOMINION U. UNDERGRAD. RSCH. J., 2020, at 3-5, https://digitalcommons.odu.edu/cgi/viewcontent.cgi?article=1086\&context=ourj [https://perma.cc/PT94-83A8]. 
unrealized. ${ }^{48}$ Transactional scripts are currently quite simple, helpful "when you can ask quantitative questions like amounts, temperature, weight, time and date, and other measurable items." 49 They are also sensible for entities that conduct business with "trading partners who are also moving toward using smart contracts[,]" particularly if the entity "[e]xecutes a lot of simple contracts with those partners[.]" ${ }^{150}$ In short, transactional scripts are useful for agreements that are "low risk and high volume[.]"

Because transactional scripts are helpful for automated, quantitative transactions,${ }^{52}$ much interest and attention is paid to their potential application in financial services. ${ }^{53}$ For example, as of this writing, the International Swaps and Derivatives Association (ISDA) is looking to automate standard transactions via transactional scripts. ${ }^{54}$ Standardized, automated agreements could significantly streamline transactions between contracting parties. ${ }^{55}$ Moreover, any time an industry uses standardized contracts, the regulatory burden is lightened, and a self-executing standardized script could further simplify regulatory efforts. ${ }^{56}$

After financial services, the next phase of adopters will likely be systems and industries that require public recordkeeping, such as real estate

48. An amusing number of articles for practitioners assure lawyers that "[s]mart contracts won't steal your job." Dan Puterbaugh, The Future of Contracts: Automation, Blockchain, and Smart Contracts, 34 No. 10 ACC DocKET 48, 51 (2016). See also Judah A. Druck, "Smart Contracts" are Neither Smart nor Contracts. Discuss, 37 No. 10 BANKING \& Fin. SERviCES POL’y REP. 5, 5 (2018) ("smart contracts (in their current form) provide few practical benefits, and will do little to remove lawyers from anything but the simplest of transactions."); Susan George, Smart Contracts: Tools for Transactional Lawyers, ST. B. TEX., https://www.texasbar.com/AM/Template.cfm? Section=articles\&Template=/CM/HTMLDisplay.cfm\&ContentID $=39994 \quad[\mathrm{https}: / /$ perma.cc/9A8Y BQRN] (last visited Jan. 24, 2020) ("Smart contracts will not make lawyers obsolete, but we will increasingly need to help clients analyze whether and how a smart contract makes sense in a particular transaction."); Dennis Kennedy, Thinking Smartly About Smart Contracts, 44 No. 1 LAW PRAC. 56, 59 (2018) (encouraging lawyers to familiarize themselves with smart contract technology). But see generally Michael Guihot, New Technology, the Death of the BigLaw Monopoly, and the Evolution of the Computer Professional, 20 N.C. J.L. \& TECH. 405 (2019).

49. Joshua Bernstein, Smart Contract Integration in Professional Sports Management: The Imminence of Athlete Representation, 14 DEPAUL J. SPORTS L. 88, 92 (2018).

50. Puterbaugh, supra note 48 , at 51 .

51. Id. at 50 .

52. Id. at 51 .

53. Bernstein, supra note 49 , at 92 .

54. Stéphane Blemus, Law and Blockchain: A Legal Perspective on Current Regulatory Trends Worldwide, CORP. FIN. \& CAP. MKTS. L. REV., Dec. 2017 (manuscript at 14), https://papers.ssrn.com/sol3/papers.cfm?abstract_id=3080639 [https://perma.cc/N4ZX-YPK9].

55. Nicolette Kost De Sevres, Bart Chilton \& Bradley Cohen, The Blockchain Revolution, Smart Contracts and Financial Transactions, 21 NO. 5 CYBERSPACE LAWYER NL 3 (2016).

56. Id. ("Smart contracts are potentially attractive to regulators, since they increase transaction security and reduce the risk of manipulation.”). 
transactions ${ }^{57}$ and Article 9 secured transactions. ${ }^{58}$ If deeds, mortgages, and financing statement records can be moved to distributed ledger technology systems, the distributed recordkeeping could ensure title ownership accuracy and eliminate the need for title searches. ${ }^{59}$ Furthermore, if the purchase of property and the related title transfer was connected to the financing transaction, transactional scripts could streamline repossession or foreclosure in the event of nonpayment: failure to make loan payments could be programmed to trigger transfer of the asset's title to the lender or secured party - with appropriate due process protections programmed in, of course. ${ }^{60}$

Other, nonpublic recordkeeping may also benefit from distributed ledger technology, and transactional scripts may one day be able to automate payments between parties upon the occurrence of triggering events. For example, a life insurance contract may be coded via a transactional script to make a payment to beneficiaries upon verification of the policy-holder's death. ${ }^{61}$ Or a transactional script for household utilities could track, say, energy use and pre-authorize appropriate payment amounts based on the relevant utility rate. ${ }^{62}$ Other applications being explored include anti-money laundering regimes, ${ }^{63}$ derivatives trading, ${ }^{64}$ copyright regimes, ${ }^{65}$ the

57. See McKinney et al., supra note 43, at 344. See also Edward D. Baker, Trustless Property Systems and Anarchy: How Trustless Transfer Technology Will Shape the Future of Property Exchange, 45 Sw. L. REV. 351, 356-57 (2015).

58. See Carla L. Reyes, Conceptualizing Cryptolaw, 96 NEB. L. Rev. 384, 402-03 (2017). Professor Reyes has written a functional, Article 9-compliant recording system entirely utilizing transactional scripts.

59. See Josias N. Dewey \& Michael D. Emerson, Beyond Bitcoin: How Distributed Ledger Technology Has Evolved to Overcome Impediments Under the Uniform Commercial Code, 47 UCC L.J. 105, 119-20 (2017); Joshua A.T. Fairfield, Bitproperty, 88 S. CAL. L. REV. 805, 808-09 (2015).

60. See Cassano, supra note 14.

61. Alan Cohn, Travis West \& Chelsea Parker, Smart After All: Blockchain, Smart Contracts, Parametric Insurance, and Smart Energy Grids, 1 GEO. L. TECH. ReV. 273, 281 (2017); Michael Abramowicz, Blockchain-Based Insurance, in BLOCKCHAIN AND THE CONSTITUTION OF a New Financial Order: Legal and Political Challenges 1, 2 (GW Legal Stud. Rsch. Paper No. 2019-12) (Ioannis Lianos et al. eds., forthcoming 2019), https://papers.ssrn.com/ sol3/papers.cfm?abstract_id=3366603 [https://perma.cc/8B4N-F5ME]; see also Michael Abramowicz, Cryptoinsurance, 50 WAKE FOREST L. REV. 671, 704 (2015).

62. Id. at 299-300; see Claire Henly, Sam Hartnett, Sam Mardell, Buck Endemann, Ben Tejblum \& Daniel S. Cohen, Energizing the Future with Blockchain, 39 ENERGY L.J. 197, 213 (2018).

63. Reyes, supra note 58, at 403-04.

64. Massimo Morini, Managing Derivatives on a Blockchain. A Financial Market Professional Implementation (2017), https://papers.ssrn.com/sol3/papers.cfm?abstract_id=3075540 [https:// perma.cc/BX8J-BC84].

65. Nick Vogel, The Great Decentralization: How Web 3.0 Will Weaken Copyrights, $15 \mathrm{~J}$. MARSHALl ReV. INTELL. PROP. L. 136, 142 (2015). 
healthcare industry, ${ }^{66}$ athletic contracts between teams and players, ${ }^{67}$ managing payments for music downloads, ${ }^{68}$ energy trading platforms,${ }^{69}$ and the issuance of securities. ${ }^{70}$ Even before these myriad applications become fully operational, transacting parties will likely find ways to incorporate transactional scripts as smaller parts of a larger transaction. ${ }^{71}$ Overall, "[t]he open question is no longer whether [transactional scripts] will become ubiquitous but whether and when they can be programmed to execute ever more complex tasks on blockchain platforms." ${ }^{, 72}$

Of course, with new technology comes new potential for errors and unintended consequences. Take, for example, a typical life insurance contract, where, upon receiving proof of death, a set amount of insurance policy proceeds will be disbursed to beneficiaries. Now imagine the same life insurance contract with a technological upgrade, encoded as a transactional script: A computer-coded "oracle" is programmed to scour the Internet continually until it finds evidence of the policy-holder's death, perhaps by finding an obituary online or by interpreting a loved one's Facebook post. ${ }^{73}$ The oracle then delivers this information as proof of death to the transactional script that records the life insurance contract, and the transactional script causes funds to be released from the insurance company's bank account and deposited into the account(s) of the beneficiary(s).

The potential errors in this scenario fairly leap off the page. What if the deceased isn't the policy holder, but is instead another person with the same name? What if the notice of a person's death is an error or a hoax? ${ }^{74}$ What if

66. Tsui S. Ng, Blockchain and Beyond: Smart Contracts, Bus. L. TodaY (Sept. 2017), https://www.americanbar.org/groups/business_law/publications/blt/2017/09/09_ng/ [https://perma.cc /N6BP-7DY9].

67. See Bernstein, supra note 49 , at $92-93$.

68. McKinney et al., supra note 43, at 342 .

69. Joseph Lee \& Vere Marie Khan, Blockchain and Smart Contract for Peer-to-Peer Energy Trading Platform: Legal Obstacles and Regulatory Solutions, https://papers.ssrn.com/sol3/ papers.cfm?abstract_id=3556260 [https://perma.cc/9YEQ-DHYT].

70. See Jonathan Rohr \& Aaron Wright, Blockchain-Based Token Sales, Initial Coin Offerings, and the Democratization of Public Capital Markets 4-5 (Cardozo Legal Stud. Rsch. Paper No. 527), (Univ. of Tenn. Legal Stud. Rsch. Paper No. 338, 2018), https://papers.ssrn.com/sol3/ papers.cfm?abstract_id=3048104 [https://perma.cc/FS6F-AGE4].

71. See Puterbaugh, supra note 48 , at 51.

72. Craig A. de Ridder, Mercedes K. Tunstall \& Nathalie Prescott, Recognition of Smart Contracts in the United States, 29 No. 11 InTELL. ProP. \& TECH. L.J. 17, 19 (2017).

73. See Jerry Brito, Houman Shadab \& Andrea Castillo, Bitcoin Financial Regulation: Securities, Derivatives, Prediction Markets, and Gambling, 16 Colum. SCI. \& TeCH. L. Rev. 144, 208-09 (2014).

74. See, e.g., Tom Kington, Twitter Hoaxer Comes Clean and Says: I Did It to Expose Weak Media, THE GUARDIAN (Mar. 30, 2012), https://www.theguardian.com/technology/ 
there's a typo in the code, and the wrong amount gets disbursed? What if the beneficiaries have closed their accounts, or no longer have access to them? What if the typo is in the beneficiaries' account numbers, and the proceeds get accidentally disbursed to third parties? Or what if the decedent passed away without leaving an online trace, and the death isn't recognized in the first place?

Some of these errors would be easy to correct-If the wrong dollar amount is disbursed, for example, the insurance company and the beneficiaries can likely work that out. Other errors are trickier, such as the funds being accidentally disbursed to third parties, who may not be identifiable at all, or may not be within a local court's jurisdiction. ${ }^{75}$

It is concerns over these kinds of errors, as well as errors we cannot yet anticipate, that hinder risk-taking in the development and adoption of transactional scripts. This and other barriers to adoption are explored in the Part below.

\section{BARRIERS TO ADOPTION}

The previous Part sketched the current state of transactional scripts, which is that they are hypothetically useful but not practically useful—yet. ${ }^{76}$ Several important problems pose significant barriers to broader adoption of transactional scripts. ${ }^{77}$

\section{A. Technological literacy and incentive}

For starters, many people don't know that smart contracts or transactional scripts exist. Even among those who have heard the terms, many do not fully understand how the technology works or have the technological literacy to enter into one.

Furthermore, some have suggested that actors in traditional contracting scenarios are specifically disincentivized to facilitate transactional script development: "transaction-facilitating intermediaries like lawyers, banks, payment processors, commercial courts, and governments are sure to resist

2012/mar/30/twitter-hoaxer-tommaso-de-benedetti [https://perma.cc/DL5Q-XLLF]; Jordan Sargent, Cormac McCarthy Isn't Dead, but an Old Prankster Tricked USA Today into Reporting He Was, GAWKER (June 28, 2016), https://gawker.com/cormac-mccarthy-isnt-dead-but-an-old-prankstertricked-1782747839 [https://perma.cc/BXU7-CNJU].

75. See Wulf A. Kaal \& Craig Calcaterra, Crypto Transaction Dispute Resolution, 73 Bus. LaW. 109, 112-13 (2018).

76. See $\mathrm{Ng}$, supra note 66_(noting issues of "scalability, centralization risk, and usability").

77. See id. No doubt more barriers and potential barriers exist than those discussed here. 
the self-executing contract revolution every step of the way."78 This quotation may overstate the concern, but there is a certain lack of logic to developing technological literacy that will in turn take away part of your business model.

\section{B. Translating contracts into code}

Although a contract is conceptually a series of if-then statements (if performance, then payment; if breach, then remedies/damages), the reality of expressing language in computer code is that the translation is imperfect. ${ }^{79} \mathrm{In}$ one sense, the problem is one of semantics: the terminology used by lawyers, clients, and regulators differs from that of computer programmers, with a plausible result being that neither side understands exactly what the other thinks the contract is performing. ${ }^{80}$ In another sense, the disconnect may be differences in the understanding of what a contract actually is, and what it is promising: "Law professionals define a contract as a formal legally binding agreement between parties, while computer engineers perceive it as computer code." $" 81$

It is important here to distinguish the code from the agreement: the agreement being the parties' intentions, desires, and promises, whereas the code is merely the manifestation of that agreement. ${ }^{82}$ It may be impossible for any set of words or media to perfectly capture the parties' agreement. ${ }^{83}$

Coding natural-language contracts presents difficulties, given the syntactic and semantic richness of language. ${ }^{84}$ Traditional contracts may even have a useful component of storytelling that itself helps further a client's

\footnotetext{
78. McKinney et al., supra note 43, at 347.

79. Charlotte R. Young, Note, A Lawyer's Divorce: Will Decentralized Ledgers and Smart Contracts Succeed in Cutting out the Middleman?, 96 WASH. U. L. REV. 649, 657-58 (2018).

80. See Tom Butler, Firas Al Khalil, Marcello Ceci \& Leona O'Brien, Smart Contracts and Distributed Ledger Technologies in Financial Services: Keeping Lawyers in the Loop, 36 No. 9 BANKING \& FIN. SERVS. POL'Y REP. 1, 1 (2017) (“'[M]ore attention should be paid to bridging the yawning gap between a smart contract's legal semantics, business semantics and regulatory semantics and its denotational semantics and ensuring provenance, while guaranteeing the empirical fidelity of a contract's operational semantics.") (emphasis in original) (footnotes omitted).

81. Blemus, supra note 54, at 13. See also Trevor I. Kiviat, Note, Beyond Bitcoin: Issues in Regulating Blockchain Transactions, 65 DUKE L.J. 569, 607 (2015) ("[T] he task of encoding the legal subtleties and nuances that underlie even the most basic contract poses significant programming challenges.").

82. See Kolber, supra note 42, at 220-21 (giving as an example The DAO's problematic code, which did not reflect the parties' actual agreement).

83. See id. at 219.

84. Allen, supra note 11, at 21-25.
} 
goals. ${ }^{85}$

Many people are working to develop transactional script protocols and best practices that will marry lawyers' intentions with computer programming realities ${ }^{86}$ but some skeptics have suggested that the more readable a contract is to humans, the less it is to computers — and vice versa. ${ }^{87}$ On the other hand, one company claims to have developed a machine-readable English programming language, Lexon. ${ }^{88}$

This difficulty becomes significantly more complex in the context of international transactions, where parties from different legal systems may themselves have different understandings of what constitutes a contract. ${ }^{89}$ If the parties themselves struggle to articulate the nature of their promises and obligations to each other, programming such promises in computer code will likely be even more difficult.

\section{Inflexibility}

One of the ideals of distributed ledger technology overall is its certainty: a truly decentralized, ${ }^{90}$ immutable ${ }^{91}$ system means that transactions cannot be unwound. ${ }^{92}$ Yet this very feature is also a transactional script's Achilles' heel:

85. Susan M. Chesler \& Karen J. Sneddon, Once Upon a Transaction: Narrative Techniques and Drafting, 68 OKLA. L. REV. 263, 295 (2016).

86. See e.g., Christopher D. Clack, Vikram A. BaKshi, \& Lee Braine, SMart Contract Templates: Foundations, Design Landscape and Research Directions, 1 (2017), https://arxiv.org/pdf/1608.00771.pdf; see also CHRISTOPHER D. ClACK, VIKRAM A. BAKSHI, \& LEE BRAINe, SMART CONTRACT TEMPLATES: ESSENTIAL REQUIREMENTS AND DESIGN OPTIONS, 1 (2016), https://arxiv.org/pdf/1612.04496.pdf [https://perma.cc/4SV9-QPTE].

87. James Hazard \& Helena Haapio, Wise Contracts: Smart Contracts that Work for People and Machines, in TRENDS AND COMMUNities of Legal INFORMATICS: ProceEdings OF THE 20TH INTERNATIONAL LEGAL INFORMATICS SYMPOSIUM IRIS 20174 fig.1 (Erich Schweighofer et al. eds., 2017), https://papers.ssrn.com/sol3/papers.cfm?abstract_id=2925871. But see LEXON, http://lexon.tech/ (last visited Jan. 24, 2021) (purporting to provide a computer coding language that is "human readable like natural language.").

88. See LEXON, supra note 87.

89. I am grateful to Rita Christopher for this insight.

90. For an analysis of whether blockchain technology is truly decentralized, see Michele Benedetto Neitz, The Influencers: Facebook's Libra, Public Blockchains, and the Ethical Considerations of Centralization, 21 N.C. J. L. \& TECH. 41, 48-49 (2019); Angela Walch, Deconstructing "Decentralization": Exploring the Core Claim of Crypto Systems, in CRYPTO ASSETS: LEgAL \& MONETARY PERSPECTIVES (Chris Brummer ed., 2019).

91. For a discussion of the use of the term "immutable" with regard to distributed ledger technology, see Angela Walch, The Path of the Blockchain Lexicon (and the Law), 36 REV. BANKING \& FIN. L. 713, 735-45 (2017).

92. See Schrepel, supra note 17, at 328-31 (identifying five "key characteristics" of blockchain technology, including pseudonymity, distributed architecture, peer-to-peer transmission, consensus blockchain validation, and data immutability). 
once programmed, the transactional script will execute exactly as written, bugs and all. Any ability to modify or terminate a transactional script must be programmed into it from the outset.

This certainty of performance creates "debilitating inflexibility" 93 that would-be transactional script-ers are understandably wary of: "[W]e know today that firms consider contractual flexibility to be a crucial strategic issue." 94 Lawyers and their clients rely on not only a written contract's "linguistic ambiguity," but also its "enforcement discretion." 95 If contracting parties are in fact counting on the malleability of language and the ability to choose among remedies, an imperfectly-programmed (or even a perfectlyprogrammed) transactional script cripples both these strategic advantages.

\section{Enforcement}

Assuming the technological literacy to enter into a transactional script smart contract is present, ${ }^{96}$ the most significant barrier to adoption of the technology is the uncertainty of how to undo or remedy the real-world results of a transactional script gone wrong. Until parties are confident that the contractual intent will be carried out by the transactional script or enforced by some external error-correction mechanism, parties will be slow to adopt this new technology. And given that the technology has the potential for significant economic advantages,${ }^{97}$ sluggish innovation and implementation would be a shame.

Transactional scripts will have pre-programmed performance and execution, but in some situations, the performance and execution undertaken by the transactional script will not be that which the parties intended. Mistakes are inevitable. A lost geotag may show that delivery has not occurred when in fact it has. ${ }^{98}$ The parties will need to confirm receipt and send payment even though the transactional script will not recognize that delivery has occurred. A typo in a real estate transaction script may transfer title of a property for less than the intended purchase price or may

93. Druck, supra note 48, at 7.

94. Jeremy M. Sklaroff, Smart Contracts and the Cost of Inflexibility, 166 U. PA. L. REV. 263, 302 (2017).

95. See id. at 264.

96. See supra Part III.A.

97. See supra Part II.B.

98. See Katherine Davison, Why Is Proof of Location Important for Digital Assets?, supra note 18. ("We integrate with the scale or the weighbridge and when the truck delivering that green crosses over the weighbridge, we then create a digital asset in our system and that digital asset can be recorded on a chain as well, and that then becomes the asset itself."). 
unintentionally transfer title to another party. If the transfer is for less than the intended purchase price, the seller could seek the remaining balance owed from the buyer, in court if necessary. If, however, title was transferred to another party, the buyer and seller would need to track down that third party in order to have title to the property transferred back. The third party has no economic incentive to do so, and if that third party is unidentifiable, or in a jurisdiction outside the reach of US courts, title to the property may be unrecoverable..$^{99}$

In these situations, and particularly in situations where the error has caused conflict, parties may need to turn to some kind of enforcement structure outside the transactional script, such as relying on statutes, courts, or alternative dispute resolution techniques to ensure the parties' contractual intent is met. Of course, this seeking of outside enforcement is diametrically opposed to the libertarian ideal of distributed ledger technology: parties dealing directly with one another, without intermediaries (especially governmental ones). ${ }^{100}$ Moreover, the efficacy of all available enforcement mechanisms is suspect at best. ${ }^{101}$ Without reliable enforcement mechanisms, parties must be prepared to "absorb[] the inherent risks of an automated contract" 102 or simply avoid using transactional scripts until the enforcement mechanisms are reliable. ${ }^{103}$ Part IV analyzes the available enforcement mechanisms, critiquing each.

\section{Possible ENFORCEMENT MECHANISMS ARE ALL IMPERFECT}

The previous Part identified a few barriers to widespread adoption of transactional scripts, including the difficulty of translating contracts into code, the inflexibility of transactional scripts' performance and execution, and the uncertainty of enforcement mechanisms available in situations where a

99. Kaal \& Calcaterra, supra note 75 , at $112-13$. This hypothetical assumes that legal title to real property is recorded on a blockchain via a token or "colored coin" system. See Steve Walters, What are Colored Coins? The Ultimate Guide, UnBLOCK (Apr. 27, 2018), https://unblock.net/whatare-colored-coins/ [https://perma.cc/YY9Q-34TB]. Even if legal title to the property was transferred to an unresponsive third party, the physical nature of the property would be unchanged - this may, however, turn the buyer into a squatter.

100. See Schrepel, supra note 17, at 328-29.

101. See infra Part IV.

102. McKinney et al., supra note 43, at 345. Parties are more likely to absorb risks if those risks are low. See id at 328. See also Victor Li, Bitcoin's Useful Backbone Blockchain Technology Gains Use in Business, Finance and Contracts, ABA J., Mar. 2016, at 31 ("Would you buy a house based on a smart contract? Probably not. But would you buy something on Amazon where you'd agree to release money only after the delivery drone crosses a certain point? Maybe.").

103. See Christopher, supra note 29, at 161-66 (conceptualizing how parties rely on a combination of trust and reliable enforcement mechanisms when entering into contracts). 
transactional script's execution is misaligned with the parties' actual intent. This Part analyzes available enforcement mechanisms in more detail. ${ }^{104}$ Again, as used in this Article, "enforcement" does not mean ensuring the performance of the contract as it is written-transactional scripts are selfenforcing in that regard. Rather, the term "enforcement" means ensuring that the contract is performed according to the parties' intent, and that where performance does not align with parties' intent, the errors in execution can be unwound and corrected. ${ }^{105}$

So far, most legal standards about distributed ledger technology and transactional scripts have come in the form of "soft law" rather than "hard law"-guidance memoranda, position papers, and the like, as opposed to statutes and court rulings. ${ }^{106}$ This may be because the technology is so new that likely problems are not understood well enough to legislate appropriate solutions, ${ }^{107}$ because regulators remain siloed from one another despite blockchain technology disrupting multiple sectors simultaneously, ${ }^{108}$ or because there has been no significant blockchain litigation that required development of relevant, decisive common law doctrine. Early signs from "hard law" sources are not encouraging, as will be discussed below.

\section{A. Statutory Law}

As has often been the case throughout American legal history, the development of transformative technologies leads almost immediately to cries from legal experts that the new technology must be regulated in order to keep

104. Allen et al. introduced the term "dispute resolution possibility frontier," or DRPF. Darcy W. E. Allen, Aaron M. Lane \& Marta Poblet, The Governance of Blockchain Dispute Resolution, 25 HARV. NEGOT. L. REV. 75, 75 (2019).

105. See Werbach \& Cornell, supra note 12, at 318 (asserting that the role of contract law is as a "remedial institution").

106. See Blemus, supra note 54. The fact that U.S. regulators are issuing "mostly non-binding" "positions" on fintech issues appears to be influencing regulators worldwide, such as those in the European Union, Canada, Hong Kong, Japan, and Singapore. Id.

107. As a general principle, statutes and regulations dealing with developing technology should not be passed until the technology and its related issues are fully understood. See, e.g., Tracy Hresko Pearl, Fast \& Furious: The Misregulation of Driverless Cars, 73 N.Y.U. ANN. SURV. AM. L. 19, 71 (2017) (critiquing state legislatures' passage of laws regulating nascent driverless car technology as overregulating relatively safe autonomous systems and underregulating more dangerous semiautonomous systems).

108. See Saule T. Omarova, Technology v. Technocracy: Fintech as a Regulatory Challenge (Cornell Legal Stud. Rsch. Paper No. 20-14, 2020), https://papers.ssrn.com/sol3/ papers.cfm?abstract_id=3545468 [https://perma.cc/8BGR-B32K]. 
the public safe. ${ }^{109}$ Numerous pieces of legal scholarship examining the nascent technology of transactional scripts have already called for governmental regulation; ${ }^{110}$ however, these articles seem unclear on what exactly should be regulated or what those regulations would accomplish. Should the government be regulating distributed ledger technology itself, or the appropriate uses for the technology, or who can use it and under what circumstances? The literature has reached no consensus on these issues. This Subpart analyzes legislative efforts at both the federal and state levels. (Although one exciting attribute of transactional scripts is their ability to cross borders, this Subpart addresses U.S. law only.)

\section{Federal Legislation}

Federal legislation may not be conceptually appropriate for transactional scripts, given that they are in essence a technological upgrade of contracts, traditionally an area of state law authority. On the other hand, given the ease with which transactional scripts can cross state and national boundaries, and the speed with which technological innovations are being pursued, a coherent national legal framework may be beneficial. For example, Congress passed the Electronic Signatures in Global and National Commerce ("E-SIGN") law in 2000, which broadly authorized the validity of electronic signatures on contracts. ${ }^{111}$ A similar federal law could address the legality, enforceability, and error-correction mechanisms applicable to transactional scripts. Such a federal law could resolve the burgeoning state law patchwork described below. ${ }^{12}$ The difficulty here would be that the technology is so new, and its innovative potential so significant, that national legislation can only be reactionary; proscriptive legislation is unlikely to correctly diagnose, let alone appropriately resolve, potential legal problems.

One additional concern about transactional scripts is the consumer

109. See Tracy Hresko Pearl, Hands Off the Wheel: The Role of Law in the Coming Extinction of Human-Driven Vehicles (2019), https://papers.ssrn.com/sol3/papers.cfm?abstract_id=3400945 [https://perma.cc/3PL8-GUWC] (comparing the legal landscapes of the turn of the 20th century, when American society transitioned from horse to automobile transportation, to the modern nascent transition from human-driven to autonomous vehicles).

110. E.g., Phillip Paech, The Governance of Blockchain Financial Networks, 80 MoD. L. REv. 1073, 1076-77 (2017) ("[B]lockchain financial networks cannot remain outside the regulatory perimeter."); Brito et al., supra note 73, at 221.

111. Electronic Signatures in Global and National Commerce Act, Pub. L. No. 106-229, 114 Stat. 464 (2000); 15 U.S.C. $\$ 7001-7031$.

112. See infra Part IV.A.2. Of note, the federal E-SIGN legislation is expressly preempted by state Uniform Electronic Transaction Act laws. 15 U.S.C. § 7002(a). 
protection issues posed when contracting on a new technological platform. ${ }^{113}$ Just as E-SIGN contains requirements regarding consumer protection issues, ${ }^{114}$ federal law on transactional scripts could clarify consumer protection requirements and norms. Unfortunately, a more detailed discussion of the consumer protection issues in transactional script smart contracting is beyond the scope of this Article.

\section{State Legislation}

Despite utter lack of clarity regarding what problems exist or how government can appropriately address them, state legislatures are taking up distributed ledger technology legislation left and right, "resulting in a regulatory mishmash" that might well be making things worse instead of better. ${ }^{115}$

Some state blockchain (or distributed ledger technology) laws are being passed for quite specific purposes. For example, a small number of states have passed laws that authorize distributed ledger technology use in corporate recordkeeping. ${ }^{116}$ Vermont has passed a law regarding the evidentiary admissibility of records stored on distributed ledger technologies, ${ }^{117}$ while Arizona has specifically prohibited the use of distributed ledger technology to track firearm ownership. ${ }^{118}$ A few states have passed laws that simply direct state agencies to explore or foster blockchain or distributed ledger technology

113. See, e.g., Danielle D'Onfro, Smart Contracts and the Illusion of Automated Enforcement, 61 Wash. U. J.L. \& POL'Y 173 (2020); Randall Duran \& Paul Robert Griffin, Smart Contracts: A Catalyst of the Next Global Financial Crisis?, J. Fin. Reg. COMPLiance (2019), https://ink.library.smu.edu.sg/cgi/viewcontent.cgi?article=6106\&context=sis_research [https:// perma.cc/BZ7R-S24P] (considering potential systemic risks as well as consumer protection issues such as lack of transparency and misuse).

114. 15 U.S.C. $\S 7001(\mathrm{c})$.

115. Carla L. Reyes, Moving Beyond Bitcoin to an Endogenous Theory of Decentralized Ledger Technology Regulation: An Initial Proposal, 61 VILL. L. REV. 191, 211 (2016).

116. E.g., CAL. CORP. CODE $\S \S 204(a)(12)(A), 2603$ (a)(12)(a) (West, Westlaw through ch. 372 of 2020 Reg. Sess.); Del. CODE tit. 8, § 224 (West, Westlaw through ch. 292 of the 150th Gen. Assemb.); S.B. 1859, 2019 Leg. (Tex. 2019); H.B. 185, 2019 Leg. (Wyo. 2019). Vermont law even authorizes "blockchain-based limited liability companies," or BBLLCs, "a business that utilizes blockchain technology for a material portion of its business activities ...." VT. STAT. ANN. tit. 11, § 4172 (West, Westlaw through Acts 1-159, 161-169, 171-179, M-1-M-12 of the Adjourned Sess. of the 2019-2020 Vt. Gen. Assemb.). Laws are pending in additional states. For continuously updating information, see Paul Hodnefield, Blockchain and Distributed Ledger Laws: State-by-State Adoption, Corporation Service Company, with Practical Law Finance, THOMPSON REUTERS PRAC. L., (last visited Jan. 24, 2020).

117. VT. Stat. ANN. tit. 12, § 1913 (West. Westlaw through Acts 1-159, 161-169, 171-179, M1-M-12 of the Adjourned Sess. of the 2019-2020 Vt. Gen. Assemb.).

118. ARIZ. Rev. StAT. ANN. § 13-3122 (West, Westlaw through 2d Reg. Sess. of the 54th Leg.). 
use. ${ }^{119}$ This may be partially to encourage cost-saving technological development and partially a legislature's desire to signal to distributed ledger technology investors that the state is amenable to business development. ${ }^{120}$

As of this writing, the most common state statutory addition regarding blockchain and distributed ledger technology is to states' Uniform Electronic Transactions Acts. ${ }^{121}$ UETA is designed "to remove barriers to electronic commerce by validating and effectuating electronic records and signatures." 122 States that have amended their UETA statutes have generally done so to specifically include blockchain or distributed ledger technology in existing electronic records laws. But even where multiple states appear to be passing similar laws all with similar purposes, minor differences in the passed legislation may make for industry and legal confusion.

Several states have passed amendments to confirm that signatures and records on a distributed ledger are "electronic" signatures and records - as if there was any doubt. Arkansas law, for instance, specifies that "A signature that is secured through blockchain technology shall be considered to be in electronic form and an electronic signature" and likewise, "[a] record or contract that is secured through blockchain technology shall be considered to be in electronic form and an electronic record." ${ }^{23}$ Arizona, ${ }^{124}$ North

119. E.g., CAL. Gov’T CODE § 11546.9(a) (West, Westlaw through ch. 372 of 2020 Reg. Sess.) (directing the Government Operations Agency to appoint a blockchain working group to report on the risks and benefits of blockchain use by state government and California businesses); COLO. REV. STAT. ANN. §§ 24-37.5-105(13)-(14), 24-33.5-1904, 22-33.5-1905 (West, Westlaw through 2020 Reg. Sess.); S.B. 213, 2019 Leg., Gen. Sess. (Utah 2019); H.B. 70, 65th Leg., Gen. Sess. (Wyo. 2019). Laws are pending in additional states. For continuously updating information, see Hodnefield, supra note 116.

120. See infra notes $150-53$ and accompanying text.

121. Promulgated by the Uniform Law Commission, UETA has been adopted in every U.S. state except New York and Illinois. Electronic Transactions Act, UnIF. L. Comm'N, https://www.uniformlaws.org/committees/community-home?CommunityKey=2c04b76c-2b7d-4399977e-d5876ba7e034 [https://perma.cc/L52F-XJY3] (last visited Jan. 24, 2020).

122. Prefatory Note of Unif. Elec. TRAnSACtions ACt (NAT'L CONF. COMM'RS ON UNIF. State Laws 1999), https://www.uniformlaws.org/HigherLogic/System/DownloadDocumentFile. ashx?DocumentFileKey=2c38eebd-69af-aafc-ddc3-b3d292bf805a\&forceDialog=0 [https://perma.cc/ PX2F-PSRQ]. For example, "[i]f a law requires a record to be in writing, an electronic record satisfies the law." Unif. ElEC. TRANSACTIONS ACT § 7(c) (NAT'L CONF. COMM'RS ON UNIF. STATE LAwS 1999).

123. ARK. CoDE ANN. § 25-32-122(b)-(c) (West, Westlaw through the 2020 First Extraordinary Sess. \& the 2020 Fiscal Sess. of the 92nd Ark. Gen. Assemb. and changes made by the Ark. Code Revision Comm'n received through Dec. 15, 2020).

124. ARIZ. Rev. StAT. ANN. § 44-7061(A)-(B) (West, Westlaw through the 2d Reg. Sess. of the 54th Leg. (2020)). 
Dakota, ${ }^{125}$ Ohio, ${ }^{126}$ and Oklahoma ${ }^{127}$ laws contain substantively identical language, and statutes in South Dakota ${ }^{128}$ and Washington ${ }^{129}$ aren't far off. But Tennessee uses different terminology in an attempt to accomplish the same thing: "A cryptographic signature that is generated and stored through distributed ledger technology is considered to be in an electronic form and to be an electronic signature[;]" and "A record or contract that is secured through distributed ledger technology is considered to be in an electronic form and to be an electronic record." 130

What to make of one state using the terms "cryptographic" and "distributed ledger technology," while seven other states use the term "blockchain technology," while 42 other states' laws contain no references to any of these words?

Even among the seven states that use the term "blockchain technology," definitions differ. For example, Arizona defines "blockchain technology" as "distributed ledger technology that uses a distributed, decentralized, shared and replicated ledger, which may be public or private, permissioned or permissionless, or driven by tokenized crypto economics or tokenless. The data on the ledger is protected with cryptography, is immutable and auditable and provides an uncensored truth." 131 North Dakota's definition is

125. N.D. CENT. CODE § 9-16-19(1)-(2) (West, Westlaw through the 2019 Reg. Sess. of the 66th Legis. Assemb.).

126. OHIO Rev. CODE ANN. § 1306.01(G)-(H) (West, Westlaw through Files 78, 80 through 81, 83 through 92, 94, 103 through 104, 106 through 107, 109 and 112 through 113 of the 133rd Gen. Assemb. (2019-2020)).

127. OKLA. STAT. tit. 12A, § 15-102(9)-(10) (West, Westlaw with enacted legis. of the 2d Reg. Sess. of the 57th Legis. (2020)).

128. “'Electronic record,' a record created, generated, sent, communicated, received, or stored by electronic means. The term includes a record that is secured through blockchain technology;" and "'Electronic signature,' an electronic sound, symbol, or process attached to or logically associated with a record and executed or adopted by a person with the intent to sign the record. The term includes a signature that is secured through blockchain technology." S.D. CodIFIED LAwS § 53-12-1(8)-(9) (West, Westlaw through 2020 Sess. L., Exec. Order 20-31 and Sup. Ct. Rule 20-06).

129. '“Electronic' means relating to technology having electrical, digital, magnetic, wireless, optical, electromagnetic, or similar capabilities, including without limitation blockchain and distributed ledger technology." WASH. REV. CODE ANN. § 1.80.010 (7) (West, Westlaw through 2020 Reg. Sess. of the Wash. Legis.).

130. TenN. Code ANN. § 47-10-202(a)-(b) (West, Westlaw through the end of the 2020 Extraordinary Sess. of the 111th Tenn. Gen. Assemb.).

131. ARIZ. Rev. StAt. ANN. § 44-7061(E)(1) (West, Westlaw through 2d Reg. Sess. of the 54th Leg. (2020). This definition is similar to Arkansas' definition of "blockchain distributed ledger technology." ARK. CODE ANN. § 25-32-122(a)(1) (West, Westlaw through the 2020 1st Extraordinary Sess. and the 2020 Fiscal Sess. of the 92nd Ark. Gen. Assemb. and changes made by the Ark. Code Revision Comm'n received through Dec. 15, 2020). 
substantively identical. ${ }^{132}$ South Dakota defines the term "blockchain technology" similarly, with the notable omission of the phrase "uncensored truth." 133 Tennessee uses definitional language identical to South Dakota's, but the term defined under Tennessee law is "distributed ledger technology," not "blockchain." 134

Washington defines "blockchain" simply: "a cryptographically secured, chronological, and decentralized consensus ledger or consensus database maintained via internet, peer-to-peer network, or other similar interaction;"'135 while Nevada has the lengthiest definition:

1. "Blockchain" means an electronic record of transactions or other data which is: (a) Uniformly ordered; (b) Processed using a decentralized method by which one or more computers or machines verify the recorded transactions or other data; (c) Redundantly maintained by one or more computers or machines to guarantee the consistency or nonrepudiation of the recorded transactions or other data; and (d) Validated by the use of cryptography.

2. The term includes, without limitation, a public blockchain. ${ }^{136}$

Curiously, Arkansas statutes define both "blockchain technology" and "blockchain distributed ledger technology," 137 but only the term "blockchain

132. See N.D. Cent. CodE § 9-16-19(5)(a) (West, Westlaw through 2019 Reg. Sess. of the 66th Legis. Assemb.).

133. S.D. CodifiED LAws § 53-12-1(8)-(9) (West, Westlaw through 2019 Reg. Sess. of the 66th Legis. Assemb.) (“'Blockchain technology,' technology that uses a distributed, shared, and replicated ledger, either public or private, with or without permission, or driven with or without tokenized crypto economics where the data on the ledger is protected with cryptography and is immutable and auditable.").

134. Tenn. CodE ANN. § 47-10-201(1) (West, Westlaw through 2020 2d Extraordinary Sess. of the 11th Tenn. Gen. Assemb.) (“'Distributed ledger technology' means any distributed ledger protocol and supporting infrastructure, including blockchain, that uses a distributed, decentralized, shared, and replicated ledger, whether it be public or private, permissioned or permissionless, and which may include the use of electronic currencies or electronic tokens as a medium of electronic exchange[.]").

135. WASH. Rev. CODE ANN. § 1.80.010 (3) (West, Westlaw with all Legis. from the 2020 Reg. Sess. of the Wash. Leg.).

136. NEV. Rev. STAT. § 719.045 (West, Westlaw through the end of both the 31st and 32nd Spec. Sess. (2020)). There is a separate definition for "public blockchain," which is identical to the definition of "blockchain" except that it adds a fifth element: "Does not restrict the ability of any computer or machine to: (a) View the network on which the record is maintained; or (b) Maintain or validate the state of the public blockchain." § 719.145(5) (West, Westlaw through 31st and 32nd Spec. Sess.).

137. ARK. CoDE ANN. § 25-32-122(a)(1)-(2) (West, Westlaw through the 20201 st Extraordinary Sess. and the 2020 Fiscal Sess. of the 92nd Ark. Gen. Assemb. and changes made by the Ark. Code Revision Comm'n received through Dec. 15, 2020). The two definitions are remarkably different. Compare § 25-32-122(a)(1) (“'Blockchain distributed ledger technology' means technology that uses 
technology" is used in other portions of the law- the term "distributed ledger" does not appear anywhere else in Arkansas statutes.

Among states that do define the term "distributed ledger technology," definitions again vary. Washington defines the term as "any distributed ledger protocol and supporting infrastructure, including blockchain, that uses a distributed, decentralized, shared, and replicated ledger[;]"138 while Tennessee defines it as "any distributed ledger protocol and supporting infrastructure, including blockchain, that uses a distributed, decentralized, shared, and replicated ledger, whether it be public or private, permissioned or permissionless, and which may include the use of electronic currencies or electronic tokens as a medium of electronic exchange[.]"139

To further belabor this point, the few states that have to date statutorily defined "smart contract" have also done so inconsistently. Arizona and North Dakota use substantively identical language, ${ }^{140}$ while Arkansas $^{141}$ and Tennessee ${ }^{142}$ define the term differently.

Why are these definitions and terminology so inconsistent? One explanation is that there is no universally accepted definition of

a distributed, decentralized, shared, and replicated ledger that is: (A) Either: (i) Public; or (ii) Private; (B) Either: (i) Permissioned; or (ii) Permissionless; and (C) Contains data that is: (i) Securely protected with cryptography; (ii) Immutable; (iii) Auditable; and (iv) Provides an uncensored truth[.]"), with § 25-32-122(a)(2) ("“Blockchain technology' means a shared, immutable ledger that facilitates the process of recording one (1) or more transactions and tracking one (1) or more tangible or intangible assets in a business network").

138. WASH. REv. CODE ANN. $§ 1.80 .010(6)$ (West, Westlaw through 2020 Reg. Sess.).

139. Tenn. CodE ANn. § 47-10-201 (West, Westlaw through 2020 2d Extraordinary Sess. of the 111th Tenn. Gen. Assemb.).

140. '“'Smart contract' means an event-driven program, with state, that runs on a distributed, decentralized, shared and replicated ledger and that can take custody over and instruct transfer of assets on that ledger." ARIZ. REV. STAT. ANN. § 44-7061(E)(2) (West, Westlaw through 2d Reg. Sess. of the 54th Leg. (2020); see N.D. CENT. CODE § 9-16-19(5)(a) (West, Westlaw through 2019 Reg. Sess. of the 66th Legis. Assemb.); N.D. CENT. CODE § 9-16-19(5)(b) (West, Westlaw through 2019 Reg. Sess. of the 66th Legis. Assemb.).

141. "'Smart contract' means: (A) Business logic that runs on a blockchain; or (B) A software program that stores rules on a shared and replicated ledger and uses the stored rules for: (i) Negotiating the terms of a contract; (ii) Automatically verifying the contract; and (iii) Executing the terms of a contract.” ARK. CODE ANN. § 25-32-122(a)(3) (West, Westlaw through the 2020 1st Extraordinary Sess. \& the 2020 Fiscal Sess. of the 92nd Ark. Gen. Assemb. and changes made by the Ark. Code Revision Comm'n received through Dec. 15, 2020).

142. “'Smart contract' means an event-driven computer program, that executes on an electronic, distributed, decentralized, shared, and replicated ledger that is used to automate transactions, including, but not limited to, transactions that: (A) Take custody over and instruct transfer of assets on that ledger; (B) Create and distribute electronic assets; (C) Synchronize information; or (D) Manage identity and user access to software applications.” TENN. CODE ANN. § 47-10-201(2) (West, Westlaw through 2020 2d Extraordinary Sess. of the 111th Tenn. Gen. Assemb.). 
"blockchain."143 Another possible, and troubling, explanation for the differences in these statutes from state to state may be that legislators don't understand the technology they purport to regulate. ${ }^{144}$ Either of these rationales should be enough to discourage legislatures from statutorily defining these terms - if definitions cannot be precise and accurate, they should not be codified. It is for this reason that this Article makes the case for universal adoption of the term "transactional scripts" when describing smart contracts on distributed ledger technology; ${ }^{145}$ precise and consistent definitions will further effective expansion of the technology's utility.

Furthermore, legislatures passing laws regarding blockchain and distributed ledger technology should be mindful that uniformity and consistency are virtues when it comes to technology that spans state borders. Ironically, the state statutory amendments discussed above demonstrate states making inconsistent amendments to an otherwise uniform act. Instead, "the varying definitions of blockchain and distributed ledger technology used by Arizona, Nevada, and Tennessee, and proposed by other states in amending their laws, may create unintended roadblocks." 146 By amending their states" UETA laws to include blockchain definitions of questionable accuracy, states are "making a formerly universal law not so universal[.]"147

Moreover, the wisdom of the UETA as it was originally written is that it defines electronic transactions conceptually rather than by specific technologies. ${ }^{148}$ As a result, the functional utility of transactional scripts is already within existing legal definitions of electronic transactions, and specific amendments to the laws are not necessary. ${ }^{149}$

Troublingly, states may be passing laws not for their substantial

143. A.J. Bosco, Blockchain and the Uniform Electronic Transactions Act, 74 Bus. LAW. 243, 243 (Winter, 2018-2019).

144. Lucy Kelly, What is Enabled? How “Blockchain Enabling” Legislation Fails Commercial Contracts, 16 RUTGERs J.L. \& PUB. POL'Y 1, 19-24 (2019).

145. See supra Part II.A.

146. Bosco, supra note 143, at 248.

147. Id.

148. Unif. L. COMm'N, Guidance Note Regarding the Relation BetWeEn the UNiform Electronic Transactions ACT and Federal Esign ACt, Blockchain TeChNOlogy AND “SMART CONTRACTS" 4 (2019), https://www.uniformlaws.org/HigherLogic/System /DownloadDocumentFile.ashx?DocumentFileKey=d2026984-1040-3c6f-62c8-a676b12d7bff\&force Dialog $=0$ [https://perma.cc/8BAA-GPNQ]. The Uniform Law Commission recommends against states amending their UETA statutes to include blockchain language, specifically because UETA's technology-neutral framing already encompasses new technological developments such as distributed ledger technology. Id. at 7.

149. I disagree with scholars who suggest that UETA should be amended to include blockchain and smart contract terminology. See, e.g., Jared Arcari, Note, Decoding Smart Contracts: Technology, Legitimacy, \& Legislative Uniformity, 24 FORDHAM J. CORP. \& FIN. L. 363, 392 (2019). 
regulation of distributed ledger technology and its uses, but merely to signal the state's friendliness as a home for business development. ${ }^{150}$ Several states have passed laws explicitly preventing municipalities from regulating distributed ledger technology activity, meaning that regulation can occur at the state level only, which may also be intended to create the image of a state as a blockchain-development haven. ${ }^{151}$ Although it is possible that "those jurisdictions[] which have the most Blockchain-friendly regulations will have competitive advantage in attraction of new innovative business models and companies willing to exploit them in a legal way," ${ }^{152}$ the opposite may also be borne out. Passing blockchain or distributed ledger technology lawsparticularly inept ones that do not accurately define terms or demonstrate understanding of the technology-may scare off blockchain innovators: "Businesses that want to engage in commerce via blockchain may be better served in states that choose not to make a big splash in the blockchain pool."153

\section{Policy Considerations}

Some scholars recommend that government not rush to regulate distributed ledger technology that is still in rapid development, with its ultimate uses unknown and even unimaginable. ${ }^{154}$ It seems wise that legislative and regulatory bodies resist the urge to pass rules governing distributed ledger technology. It is not currently clear exactly what problems are truly likely to be experienced related to this technology, and the likelihood of governmental bodies correctly preventing problems that have not yet emerged seems small. ${ }^{155}$ Whether because they misunderstand the technology, define it imprecisely, ${ }^{156}$ or simply cannot predict its future applications, laws and regulations passed in haste are likely to stymie positive

150. See Cohn et al., supra note 61, at 285 (asserting that Arizona's blockchain law was passed for this purpose).

151. E.g., ARIz. Rev. Stat. AnN. §§ 9-500.42, 11-269.22 (Westlaw through the Second Reg. Sess. of the Fifty-Fourth Legis. (2020)); Colo. REv. STAT. ANN. §§ 24-37.5-407(3), (6) (West, Westlaw through all Legis. of the 2020 Reg. Sess.); NEV. REV. STAT. §§ 244.3535(1), 268.0979(1) (West, Westlaw through the end of both the 31st and 32nd Spec. Sess. (2020)). Laws are pending in additional states. For continuously updating information, see Hodnefield, supra note 116.

152. Savelyev, supra note 43 , at 2 .

153. Bosco, supra note 143, at 251.

154. See, e.g., Morgan N. Temte, Comment, Blockchain Challenges Traditional Contract Law: Just How Smart Are Smart Contracts?, 19 WYo. L. REV. 87, 113-14 (2019).

155. See Michael Abramowicz, Predictive Decisionmaking, 92 VA. L. REv. 69, $70-74$ (2006) (describing mechanisms employed by public and private entities engaged in predictive decisionmaking.).

156. See Angela Walch, Blockchain's Treacherous Vocabulary: One More Challenge for Regulators, 21 NO. 2 J. INTERNET L. 1, 9 (2017). 
technological development while simultaneously failing to prevent true future threats.

Moreover, there is a mismatch between the speed of development of distributed ledger technology and legislation or regulation. The technology is rapidly developing, while legislatures and regulatory agencies ought to be thoughtful and deliberative. The worst scenario here would be laws that are quickly passed or regulations that are haphazardly promulgated which stifle innovation while failing to prevent abuses, but that are slow to be repealed or modified.

Overall, the lack of national standards and the patchwork of state laws are not reassuring would-be transactional scripting parties that errors in transaction performance can be effectively corrected. Though these laws and regulations attempt to protect users and foster development, they do not address the significant potential for transactional scripts to execute in ways counter to parties' expectations, nor do they provide a sense of security that these errors can be corrected.

\section{B. Private Law/Code Is Law}

If legislators and regulators are unlikely to correctly diagnose, prevent, or resolve errors in transactional scripting, perhaps a laissez faire approach would be better: "If you don't know what is best, let people make their own arrangements." 157 That is, let people enter into transactional scripts knowing that the performance of the contract is final, regardless of whether it's the performance both parties intended - so long as both parties understand the risks, let them live with the results. ${ }^{158}$ Such an approach requires parties to trust not only each other, but the code itself to execute as they intended. ${ }^{159}$ This kind of private law, where the parties govern their own transactions and disputes, may be "better positioned to be updated for encompassing the new factual patterns offered by [transactional script] technology." 160

157. Frank H. Easterbrook, Cyberspace and the Law of the Horse, 1996 U. CHI. LEGAL F. 207, 210 (1996).

158. See Kolber, supra note 42, at 227 ("Voluntary Agreements Should Generally Be Supported, Even Hyperliteral Ones") and 233 ("While it's possible for us to craft hyperliteral agreements, I argue that we need to be very explicit about the fact that we're doing so."); Felipe Jiminez, A Formalist Theory of Contract Law Adjudication, 2020 UTAH L. REV. 1121, 1163 (2020).

159. Jenny Cieplak \& Simon Leefatt, Smart Contracts: A Smart Way to Automate Performance, 1 Geo. L. TeCH. REv. 417, 427 (2017). Parties must trust the coder, as well. This raises potential issues of liability for the coder, as well as possibly constituting the unauthorized practice of law if the coder is "translating" a written contract to computer code. See supra text accompanying note 43.

160. Sai Agnikhortram \& Antonios Kouroutakis, Doctrinal Challenges for the Legality of Smart 
In many ways, this private-law approach comports with the libertarian ideals of cyberspace and distributed ledger technology: the idea of parties dealing directly with one another, without intermediation by government or other actors. ${ }^{161}$ "[T] here is regulation of behavior in cyberspace, but that regulation is imposed primarily through code" rather than government. ${ }^{162}$ Indeed, in a purely free-market, online environment, "software may be seen as the sole determinant for enforceability, thus bypassing the relevant rules of private law and the authority of the courts." 163

Code is law in the sense that software engages in behavioral gatekeeping, only recognizing and responding to certain user behavior. ${ }^{164}$ "[A]s opposed to traditional legal rules, which merely stipulate[] what people shall or shall not do, technical rules determine what people can or cannot do in the first place." 165 Point the wrong remote at a television and nothing will happen. The traditional form of law regulates behavior by enforcing conformity with a set of norms - commit a crime or a tort and face the consequences. "The advantage of ... regulation by code is that, instead of relying on ex-post enforcement by third parties (i.e., courts and police), rules are enforced exante, making it very difficult for people to breach them in the first place."166

There are several concerns with this private law approach to transactional script error-correction, most of which relate to consumer and market protection issues. First, code-is-law protocols do not necessarily contain the

Contracts: Lex Cryptographia or a New, 'Smart' Way to Contract?, 19 J. HIGH TECH. L. 300, 300 (2019).

161. See LAWRENCe Lessig, Code: ANd Other Laws of Cyberspace 6 (1999); Nakamoto, supra note 12, at 1; Richard A. Epstein, In Defense of the Contract at Will, 51 U. CHI. L. REv. 947, 951 (1984) (celebrating contract as exercise of individual autonomy). But see LESSIG, supra, at 6 ("The invisible hand [of cyberspace], through commerce, is constructing an architecture that perfects control — an architecture that makes possible highly efficient regulation.").

162. Lessig, supra note 161, at 20; Gillian K. Hadfield \& Barry R. Weingast, What is Law? A Coordination Model of the Characteristics of Legal Order, 4 J. LEGAL ANALYSIS 471, 473 (2012) ("legal order" does not require a nation-state enforcer, but exists where "(i) there is an identifiable entity (an institution) that deliberately supplies a normative classification scheme that designates some actions as 'wrongful' (punishable, undesirable) and (ii) actors, as a consequence of the classification scheme, forego wrongful actions to a significant extent.").

163. Paech, supra note 110, at 1076.

164. See Baker, supra note 57, at 356 (distributed ledger technologies "provide a scaffold for the development of extralegal property systems that rely on software to maintain compliance, rather than the rule of law.").

165. Samer Hassan \& Primavera De Filippi, The Expansion of Algorithmic Governance: From Code is Law to Law is Code, SPecial Issue 17, Field ACtions ScIenCe RePs. 88, 89 (2017), https://journals.openedition.org/factsreports/4518 [https://perma.cc/ZC24-HXLK].

166. Id. at 166 (emphasis in original). 
transparency or consumer protection mechanisms of public law. ${ }^{167}$ Disparate levels of bargaining power or technological literacy between the parties may lead to weaker parties entering into unfair agreements, and once entered into, the transactional script technology will execute exactly as written. Consumer protection principles mandate a mechanism by which unconscionable, illegal, and otherwise unenforceable contracts are rendered void or voidable. Transactional scripts, however, will provide this non-execution option only if programmed to do so from the outset. Unscrupulous contracting parties seeking to prey on weaker parties have no incentive to include code that provides a non-performance option.

Unfairness that results from contracting parties with unequal bargaining power may compound into systemic problems. "We can build, or architect, or code cyberspace to protect values that we believe are fundamental, or we can build, or architect, or code cyberspace to allow those values to disappear." 168 For example, powerful private actors like Facebook and Google are already monitoring private action online, and "[w]ithout appropriate legal safeguards, it is plausible that the development of blockchain technology could . . lead[] to increased surveillance." 169 It is important that "emerging autonomous systems [develop] in ways that promote economic growth, free speech, democratic institutions, and the protection of individual liberties." ${ }^{170}$ Ensuring these ideals may require some form of oversight, which purely peer-to-peer transactions lack.

Furthermore, a purely peer-to-peer, code-is-law system of governance risks adversely affecting third parties and the market as a whole: "[S]ince third parties and the market at large may also be affected [by transactional script contract performance errors], the issue of enforceability of rights cannot be left entirely to the software, even if the parties themselves agree to transact following the internal rules of the network." ${ }^{171}$ An unpoliced network of privately contracting parties may even result in collusion that can warp the

167. See Baker, supra note 57, at 361 ("Online, contract law is not the law of bargained-for exchange; it has become the law of company-dictated exchange."); See Joshua A.T. Fairfield, Smart Contracts, Bitcoin Bots, and Consumer Protection, 71 WASH. \& LeE L. ReV. ONLINE 36, 42-43 (2014).

168. LESSIG, supra note 161, at 6 .

169. Aaron Wright \& Primavera De Filippi, Decentralized Blockchain Technology and the Rise of Lex Cryptographia, 1, 53 (2015), https://papers.ssrn.com/sol3/papers.cfm?abstract_id=2580664 [https://perma.cc/2KNK-EXWA].

170. Id. at 57-58; see also Karen Levy \& Solon Barocas, Designing Against Discrimination in Online Markets, 32 BERKELEY TECH. L.J. 1183, 1185-86 (2017) (analyzing how the design of online markets can perpetuate or alleviate discrimination).

171. Paech, supra note 110, at 1076. 
free function of markets. ${ }^{172}$

\section{Online Dispute Resolution}

Transactional scripts execute as written, for better or for worse, but one approach to mitigate errors in performance (that is, the transactional script performing other than as the parties intended) is to incorporate errorcorrection or dispute-resolution mechanisms into the transactional scripts from the beginning. ${ }^{173}$ Provisions for online arbitration, crowd-sourced dispute resolution, or AI-powered solutions can be programmed into the transactional script at the time of formation. ${ }^{174}$

These on-chain dispute resolution methods are known as "online dispute resolution," or ODR, borrowing the term and the concept from the ecommerce sector. ${ }^{175}$ Parties can incorporate private dispute resolution mechanisms such as mediation ${ }^{176}$ or arbitration ${ }^{177}$ into the transactional script. ${ }^{178}$ These dispute resolution mechanisms should be designed such that any party can trigger them, and that the ODR mechanism will effectively pause the transaction until the dispute is resolved. ${ }^{179}$

The benefits of building dispute resolution into the transactional script are that resolutions can be reached more quickly and efficiently than by

172. See Dr. Thibault Schrepel, Collusion by Blockchain and Smart Contracts, 33 Harv. J.L. AND TECH. 117, 128, 130-31 (2019).

173. Bridget A. Smith \& Teresa L. Bechtold, When Smart Contracts Break: Developments in Blockchain, Smart Contracts, and Online Dispute Resolution, 36 COMPUT. \& INTERNET LAW. 1, 2 (2019).

174. See Amy J. Schmitz \& Colin Rule, Online Dispute Resolution for Smart Contracts, 2019 J. DISP. RESOL. 103, 114-22 (2019).

175. Orna Rabinovich-Einy \& Ethan Katsch, Blockchain and the Inevitability of Disputes: The Role for Online Dispute Resolution, 2019 J. DisP. RESOL. 47, 57-58 (2019); see also Amy J. Schmitz, A Blueprint for Online Dispute Resolution System Design, 2019 J. DisP. RESOL. 1, 2-3 (2019), (describing best practices for designing e-commerce ODR mechanisms).

176. James Gatto \& Elsa S. Broeker, Bitcoin and Beyond: Current and Future Regulation of Virtual Currencies, 9.2 OHIO ST. ENTREPRENEURIAL Bus. L.J. 429, 467-68 (2015), https://kb.osu.edu/bitstream/handle/1811/78477/OSBLJ_V9N2_429.pdf?sequence=1\&isAllowed=y [https://perma.cc/M8C3-3SBZ].

177. E.g., Michael Abramowicz, Cryptocurrency-Based Law 49-53 (George Washington U. L. Sch. Public L. Rsch. Paper No. 2015-9, 2015), https://papers.ssrn.com/sol3/ papers.cfm?abstract_id=2573788 [https://perma.cc/W9HW-79UF] (describing peer-to-peer blockchain arbitration); Gatto \& Broeker, supra note 176, at 467-68 (describing the use of smart oracles as adjudicators).

178. For detailed case studies of specific ODR mechanisms and providers, see Allen et al., supra note 104 , at $86-89$.

179. Schmitz \& Rule, supra note 174, at 122-23. Other recommendations from that article include the incorporation of time limits to prevent parties from using ODR as delay or hindrance tactics, and possibly requiring the maintenance of an escrow account. Id. at 123. 
litigation, ${ }^{180}$ as well as avoiding jurisdictional difficulties such as identifying parties and establishing territorial jurisdiction. ${ }^{181}$ ODR provisions can also preserve anonymity of the parties, if that is a desirable feature of the transactional script. ${ }^{182}$ ODR can also preserve parties' relationships by avoiding more formal dispute resolution such as litigation, and, if the dispute resolution mechanism is incorporated into standardized transactional scripts, provides opportunity for "large-scale redress." 183

On the other hand, private dispute resolution may not necessarily be fair to each of the contracting parties. The more powerful party may be able to force an unfair dispute resolution mechanism on the less powerful. Similarly, if parties have different levels of technological literacy, the more literate party may be able to incorporate an unfairly favorable ODR mechanism into the transactional script. Private dispute resolution necessarily removes an element of public accountability, which may result in unfair dispute resolution happening with ODR. ${ }^{184}$ Furthermore, at a meta level, an improperly- or inexpertly-programmed dispute resolution mechanism may compound errors in transactional scripts: if the contract embodied in the transactional script performs other than as anticipated and an ODR provision is triggered, but then the ODR mechanism itself misfires, the aggrieved party may be doublydisadvantaged.

\section{Public/Private Partnership}

Some scholars propose that regulators partner with code developers to build information structures that only permit compliant actions, "so that regulation is endogenously incorporated into the decentralized ledger technology and the applications running on top of the technology." 185 This builds upon the basic premise that code defines not what parties should do, but what they can do-noncompliant behavior will simply not be compatible

180. Smith \& Bechtold, supra note 173 , at 3.

181. Kaal \& Calcaterra, supra note 75, at 110 (introducing the phrase "distributed jurisdiction."). Schmitz \& Rule, supra note 174, at 105, 122 (describing paint litigation as an absurdly out-of-touch resolution mechanism because it is so time-intensive and takes place offline).

182. Kaal \& Calcaterra, supra note 75, at 109.

183. Rory Van Loo, The Corporation as Courthouse, 33 YALE J. REG. 547, 547 (2016).

184. See Rory Van Loo, Federal Rules of Platform Procedure, U. CHI. L. REV. (forthcoming 2021) (manuscript at 35), https://papers.ssrn.com/sol3/papers.cfm?abstract_id=3576562 [https://perma.cc/D8MV-CQUT].

185. Reyes, supra note 115, at 195. See also Yueh-Ping (Alex) Yang \& Cheng-Yun Tsang, RegTech and the New Era of Financial Regulators: Envisaging More Public-Private-Partnership Models of Financial Regulators, 21 U. PA. J. BUS. L. 354, 357-59 (2018); Schrepel, supra note 17, at 326. 
with code, as code can only engage with compliant behavior.

Embedding legal compliance into code that will itself execute transactions reduces the "law lag" between black-letter law changes and users' lived experience. ${ }^{186}$ In cooperation with regulators, developers can update code quickly upon recognizing bugs, implementing improvements, or adapting to regulatory changes. ${ }^{187}$

This "use of technological solutions to improve regulatory compliance" is known as "RegTech." 188 Benefits include not only reducing law lag, but also advances in machine learning that may allow properly developed code to improve itself as it runs. ${ }^{189}$ (Think what effective machine learning can do in a common-law system $!^{190}$ )

On the other hand, machine learning and transactional script code that upgrades itself may make for a legal and regulatory system that evolves on its own, which is obviously inappropriate: the public won't know what those rules are, rules could conceivably be developed differently for different parties, evolving laws may become discriminatory, and the public may come to question the very legitimacy of the framework. ${ }^{191}$

\section{E. Common Law}

Scholars are nearly unanimous on common law's ability to adapt to new technology. ${ }^{192}$ Contract doctrine has been successfully applied to vending machines, shrinkwrap agreements, and other new technologies; it will work for transactional scripts, too. ${ }^{193}$ The biggest challenge may be making sure judges understand how the technology works and what it does and doesn't

\footnotetext{
186. See Reyes, supra note 58, at 435-36.

187. See Schrepel, supra note 17, at 326.

188. Yang \& Tsang, supra note 185 , at 357 .

189. Reyes, supra note 58, at 413-14.

190. See id. at 428-30.

191. Hassan \& De Filippi, supra note 165, at 90.
}

192. E.g., RichARD A. EPSTEIN, SiMPLE RULES FOR A COMPLEX WORLD 16 (1995) ("traditional judge-made conceptions of common law are, if anything, more attuned to a complex modern world than to the simpler bygone age in which they were formulated."); Raskin, supra note 11, at 306 ("there is little difficulty situating smart contracts within existing contract law."); Rohr, supra note 12, at 7778 ("Contract law's ability to incorporate new technology demonstrates the foundational concepts that do much of contract law's heavy lifting - offer, acceptance, assent, etc. These concepts are flexible, especially in the hands of common law judges .... Judges who confront smart contracts will have similar flexibility to apply foundational contract law in different ways." (emphasis in original)); see Scholz, supra note 43, at 139, 157.

193. Rohr, supra note 12, at 77, 91-92. Technology-specific rules may develop for blockchainbased smart contracts, as happened with shrinkwrap and clickwrap agreements. Id. at 77 . 
do. ${ }^{194}$

Judges and juries are capable of undertaking many of the tasks that are likely to pose legal issues for transactional scripts, such as identifying the intent of contracting parties, determining whether a string of computer code constitutes a "writing" that will satisfy the Statute of Frauds, ${ }^{195}$ and determining liability for scrivener's errors. ${ }^{196}$ For example, various U.S. courts have already held that emails, with their electronic signatures, constitute writings that satisfy the Statute of Frauds. ${ }^{197}$

This capable common-law system, these ordinary heroes in the forms of judges and juries, will only be able to develop transactional script common law if the cases come to court, however, and that's not always going to be easy. ${ }^{198}$ For example, a plaintiff who seeks a remedy from a transactional script gone awry must be able to identify the defendant, but a counterparty to a purely online transaction may not be identifiable IRL. ${ }^{199}$ The plaintiff must also bring suit in a court that has jurisdiction over the defendant; again, not always possible for purely online transactions. ${ }^{200}$ And the court must have the power to enforce any remedy it orders. Consider the life insurance contract transactional script described above, where upon finding online confirmation of the insured's death, funds are automatically released to beneficiaries. ${ }^{201}$ If a typo in the transactional script accidentally releases funds to a third party instead of the intended beneficiaries, the third party must be identified, which

194. Id. at 92 .

195. See $\mathrm{Ng}$, supra note 66 (" $[\mathrm{I}] \mathrm{n}$ the future, litigation attorneys may no longer be litigating the 'four-corners' of the contract, but rather expanding into the intent of the code.")

196. See Susan George, Smart Contracts: Tools for Transactional Lawyers, 81 TEX. B.J. 403, 403 n.2 (2018) ("A body of law on who bears responsibility - and how much - for when a code malfunctions while executing a smart contract will undoubtedly develop and evolve over time.").

197. E.g., Cloud Corp. v. Hasbro, Inc., 314 F.3d 289, 295-96 (7th Cir. 2002); Central Ill. Light Co. v. Consolidation Coal Co., 235 F. Supp. 2d 916, 919 (C.D. Ill. 2002), aff'd, 349 F.3d 488 (7th Cir. 2003); Roger Edwards, LLC v. Fiddes \& Sons, Ltd., 245 F. Supp. 2d 251, 261 (D. Me. 2003); Int'1 Casings Grp., Inc. v. Premium Standard Farms, Inc., 358 F. Supp. 2d 863, 874 (W.D. Mo. 2005); PayoutOne v. Coral Mortg. Bankers, 602 F. Supp. 2d 1219, 1225-26 (D. Colo. 2009); Gillis v. Wells Fargo Bank, N.A., 875 F. Supp. 2d 728, 735 (E.D. Mich. 2012); Williamson v. Bank of New York Mellon, 947 F. Supp. 2d 704, 710-11 (N.D. Tex. 2013); McClare v. Rocha, 86 A.3d 22, 26-27 (Me. 2014). But see Toghiyany v. AmeriGas Propane, Inc., 309 F.3d 1088, 1091-92 (8th Cir. 2002).

198. See Spencer Williams, Predictive Contracting, 2019 Colum. Bus. L. REv. 621, 625-29 (2019) (noting the slow evolution of contract terminology as cases are litigated and suggesting a technological system that can track and then predict effectiveness of contract terms).

199. See McKinney et al., supra note 43, at 330.

200. Kaal \& Calcaterra, supra note 75, at 128, 135. For broader discussions of personal jurisdiction and the internet, see generally Matthew L. Perdoni, Revising the Analysis of Personal Jurisdiction to Accommodate Internet-Based Personal Contacts, 14 U. D.C. L. REV. 159, 162-66 (2011); Zoe Niesel, \#PersonalJurisdiction: A New Age of Internet Contacts, 94 IND. L.J. 103 (2019). See also, e.g., Abdouch v. Lopez, 829 N.W.2d 662, 676 (Neb. 2013).

201. See supra text accompanying notes $61,73-75$. 
may already be a difficult hurdle when utilizing a pseudonymous technology like distributed ledger technology. ${ }^{202}$ Once the third party can be identified, they must be sued in a court that can exercise personal jurisdiction over them as well as exercise subject matter jurisdiction over the dispute. The third party may well be overseas, outside the territorial jurisdiction of the United States. Then, if judgment is rendered against them, the court must have some authority over the third party so as to enforce the judgment.

Even assuming these obstacles can be overcome, development of common law in this area will be slow, and application of existing doctrine to new technology will have a patchwork appearance for some time. The slow pace of development and consensus-building among jurisdictions may lead to over-emphasis on early cases. ${ }^{203}$

\section{CONCLUSION}

Transactional scripts may have great potential: efficiency, security, etc., but the uncertainty of their ability to perform as the parties intended-and uncertainty about whether any errors can be effectively unwound - is slowing adoption and expansion of their use. No one enforcement mechanism seems perfect: statutory and regulatory responses seem inadequate, common law development is slow, public-private partnership lacks transparency, and private law places too much risk on unsophisticated parties. Once the technology is defined carefully and consistently, and once it is clear what enforcement mechanisms are available for parties to unwind erroneous transactional scripts, the technology can develop more quickly and transactional scripts will become more prevalent and useful.

202. See Schrepel, supra note 17, at 330-31 (identifying pseudonymity as a hallmark of blockchain and distributed ledger technology).

203. E.g., Bacina, supra note 1, at 20 (engaging in significant analysis of a 2005 Singapore case, S M Integrated Transware Pty Ltd. v. Schenker Singapore (Pte) [2005] 2 SLR(R) 651, 654, which held that "although e-mails were files of binary (digital) information in their transmitted or stored form," this digital information did constitute a "writing."). 